\title{
PEDRO MANUEL XIMÉNEZ DE URREA, DRAMATURGO MISÁNTROPO
}

\author{
I Patron que nauegas en mar tantos años \\ avn que cossarios y vientos den guerra \\ no vendas la naue por salir a tierra \\ porque hallaras mayores engaños \\ veras los ganados muy grandes rabaños \\ los lobos y perros venir contra ellos \\ y avn los que los guardan mantenerse dellos \\ y los dueños y amos venir muy estraños ${ }^{1}$.
}

Con estas palabras el pastor Mingo empieza la breve pieza - tan sólo trescientos cuarenta y un versos - que lleva el título Egloga llamada Naue de seguridad, compuesta por don Pedro Manuel de Vrrea. Sabemos que es pastor el que habla porque el argumento que encabeza el texto impreso nos lo declara, "Primeramente entro vn pastor llamado Mingo" ( $\mathrm{xciij}^{\mathbf{0}}$ ), y un hondo interés en los problemas que acosan la vida del campo también da a conocer su estirpe. En sus octavas de arte mayor, sin embargo, el desarrollo del tema que introduce en los versos citados mejor suena a sermón y el tono es decididamente erudito, así como podría esperarse en virtud de lo dicho a continuación en el argumento: "començando de dezir los males deste mundo" (xciij v ${ }^{\circ}$ ). Su inventario abarca tales perversidades como amistades fingidas, virtudes abandonadas, engaños, fraudes y perjurios. Porque se siente tan molesto al contemplar lo que pasa en su mundo, prefiere dejar atrás a la patria, haciéndose criado de un marinero para acompañarle

1 Pedro Manuel Ximénez de Urrea, Cancionero de todas las obras, Juan de Villaquiran, Toledo, 1516, f. xciij v $\mathrm{v}^{\circ}$. Toda cita lleva la puntuación original, pero he desarrollado las abreviaturas; de aquí en adelante, identifico la fuente por el número de folio. 
adondequiera que navegue: "yr quiero / mejor donde el fuere que aqui do moramos" (xciiij r ${ }^{\circ}$ ).

Hay poco nuevo en todo esto. Es consabido que por los siglos los dramaturgos han lamentado las malas costumbres de su época, infundiendo a sus obras la impotencia o resignación de quienes contemplan a sus coetáneos desprovistos de razón y virtud, buscando ellos mismos fomentar cambios y mejoría. Sus protagonistas desafectos unas veces se ausentarán de su sociedad para buscar alivio en la soledad, fijándose en lo malo y olvidándose de los placeres que también ofrece la vida; lo mismo ha hecho Mingo, según su antiguo compañero Bertol:
Zagal bien mañoso discreto y prudente medio palaciego en cosas de gala ya no vas a villa a ver la zagala y dante la guerra pascual y llorente (xciij v ${ }^{\circ}$ ).

Los que nada más perciben la amoralidad, pueden sentirse empujados hacia un destierro para salvarse del gran peligro que creen que los amenaza; Mingo declara tal propósito:

I a la fe Bertol con esto concluyo dexar quiero el cargo cabaña y avn hato porque enla tierra ay tan falso trato por donde me pierdo me daño y destruyo (xciij $r^{\circ}$ ).

No sólo dramaturgos, sino también poetas, novelistas y filósofos, puede que se acuerden que su edad no es de las mejores. Pedro Manuel Ximénez de Urrea no inventó nada único al escandalizarse por la vileza del Aragón a su alrededor. Lo que sí debe extrañarnos es que todo esto, $¡$ sirve para introducir una pieza romántica! Inmediatamente después de que sale Mingo en busca de su "naue de seguridad" se inicia una obra muy al estilo de Juan del Encina, que versa sobre el amor entre campesinos, algunas veces en contraste con el mismo sentimiento entre cortesanos, aunque no en este caso: "Vino luego Benito, hijo de Mingo, $\mathrm{y}$, demandando por su padre, quando supo que se auia ydo, tomo tal alteracion que cayo amortescido en tierra"' (xciij vo ). Por penado que esté por la partida de su padre, también está afligido de otro dolor, su amor por Menga; para que se le sane, aconseja un físico que venga la zagala para hablarle y así lograr resucitarlo: 
Leuanta noticia zagal bien amado pues que te visita la que tanto quieres $[\ldots]$ que si te leuantas de estar tan tendido bien podra ser que te aya abraçado $\left(\right.$ xciiij v $\left.^{\circ}\right)$.

Es eficaz la promesa: entre asustado e inflamado, se despierta, exclamando: "Uala me dios que oyo dezir"' (xcv ro $)$. El ambiente es ahora, repentinamente, todo alegría, y los enamorados, el físico y Bertol empiezan a irse cantando un villanctco. Aunque éste había especificado la manera de su partida - "cantemos cantemos con gozo chabado" - las palabras denotan algo distinto, por referirse a una falta de gozo:

\section{Buscar plazer es cordura $y$ avn que en mi yo no le hallo fingido quiero mostrallo $\left(\mathrm{xcv} \mathrm{r}^{\circ}\right)$.}

El fin del villancico, de veras es de tono opuesto al contentamiento que acaba de verse, sólo diecisiete versos antes, y el tema ya toca en lo universal y no sólo en lo particular:

$$
\begin{aligned}
& \text { Yo acuerdo siempre dezir } \\
& \text { avn que muy triste me siento } \\
& \text { que nadie siente tormento } \\
& \text { sino al tiempo de morir }\left(\mathrm{xcv} \mathrm{r} \mathrm{r}^{\circ}\right. \text {. }
\end{aligned}
$$

Es claro que la pieza dista en algo de las églogas encinianas que eran su fuente y modelo. Tuvo buena razón Eugenio Asensio al escribir que "[e]l villancico terminal adolece del mismo tono desengañado que marca buena parte de los escritos tardíos de Urrea. No ha conseguido armonizar los motivos amoroso y moral, y la desaparición de Mingo y su sustitución por Benito parecen un truco poco afortunado de prestidigitación literaria'"2.

Para tratar de entender por qué los dos impulsos opuestos, la agria crítica y el alegre contentamiento, cargan la misma brevísima obra, debemos traer a cuentas la personalidad de su creador, por lo menos hasta el grado que presumimos conocer a Urrea a partir de las huellas que encontramos en sus escritos, las cuales

${ }^{2}$ En su edición de las Églogas dramáticas y poesías desconocidas de Urrea, Imprenta de C. Bermejo, Madrid, 1950, p. xxx (Joyas Bibliográficas, 5). 
discuten los tres modernos investigadores de la obra de Urrea, Martín Villar, Asensio y Roger Boase.

Villar editó el Cancionero de $1513^{3}$; su introducción peca en cierto modo de patriachiquista, pero no hemos de negar que nos legó la mayoría de los datos que hoy poseemos de Urrea, y Asensio (p. xv) y Boase ${ }^{4}$ reconocen su deuda por ello. Sabemos que Pedro Manuel nació, con toda probabilidad, en 1486, fecha que se fija aritméticamente de esta manera: en una poesía suya dice haberse casado teniendo diecinueve años, mientras Villar cita las "capitulaciones matrimoniales celebradas en Trasmoz, pueblo del partido judicial de Tarazona, en los días 28 y 30 de Abril del año 1505 " (p. viii). El editor zaragozano tuvo acceso a dos fuentes biográficas manuscritas al parecer ya imposibles de consultar, pero las pruebas que cita dejan claro el hecho de que fuera nuestro autor no poco arisco: "No dejó nuestro D. Pedro de mostrar ardimento y varonil entereza, ya que no en guerras de infieles, porque en su tiempo no las hubo, en contiendas civiles, y principalmente en la que se promovió contra los de Añón por ciertas aguas que le tomaron"' (p. x). Refiriéndose a esta contienda con los familiares del conde de Ribagorza, señores de Añón, Asensio lo caracteriza como "un personaje caballeresco, casi quijotesco" (p. xvi).

El profesor Boase, últimamente el más entusiasta investigador de la vida de Pedro Manuel, ha sacado provecho de sus predecesores y además "makes extensive use of sixteenth-century chronicles not drawn on by previous students of the poet's work" ("Inquiry", p. 37). Ofrece un catálogo de sucesos que indican llanamente que Urrea tenía confianza con los más prepotentes nobles aragoneses y sus familias. También confirma la presentación por Villar de un hombre reñido a menudo con sus vecinos; efectivamente Boase se refiere a la rivalidad Urrea-Ribagorza como una "private vendetta" ("Inquiry", p. 37). Pero poco después de que nuestro autor publica su Cancionero de todas las obras en 1516, lo perdemos de vista: " $t$ there is no mention of Urrea's name in the chronicles after 1518" ("Inquiry", p. 45). Boase pudo fijar, sin embargo, un terminas ad quem para su muerte, visto que el 17

${ }^{3}$ Cancionero de D. Pedro Manuel Ximénez de Urrea, "Publicado por la Excma. Diputación de Zaragoza, teniendo á la vista la única y hoy rarisima edicion que se hizo en Logroño en 1513" [por Arnao Guillén de Brocar], Imprenta del Hospicio Provincial, Zaragoza, 1878.

4 “'Pedro Manuel Ximénez de Urrea (1486-c.1530): A Biographical Inquiry", Iberoromania, 6 (1977), pp. 36-37, n. 1 (lo identifico abajo por "Inquiry"). 
de noviembre de 1536 su mujer, doña María de Sesé, hizo su testamento, en el cual se describe como viuda de don Pedro Manuel Ximénez de Urrea ("Inquiry", p. 45).

A pesar de la pobreza de datos biográficos, en virtud de las huellas recogidas de sus obras literarias se puede declarar que el más destacado determinante de la personalidad pública de Pedro Manuel - y no dudo que también de la privada - fue haber nacido segundón del Conde de Aranda. Su hermano mayor, Miguel, heredó el título y la parte del león de la apreciable fortuna de su padre, don Lope Ximénez de Urrea, a quien se le otorgó el condado en 1488 . Asensio habla de la "secreta amargura de haber nacido segundón" (p. xvii) y exclama sobre la pena que le causó: "QQué torcedor era para él su condición de segundón o, como él se nombra [... ] «segundo y desposeído / de la hazienda»!" (p. xix). Uno debe preguntarse si el adjetivo de Asensio en la frase "secreta amargura" es válido, pues un tono misantrópico (y misógino) es patente, como se verá a continuación, en muchas obras del Cancionero de 1516, y no sólo en la égloga de Mingo.

Su única herencia fue Trasmoz, en aquella época al parecer - a su parecer - nada más que un rudo lugarejo, forzosamente llegó a ser su domicilio cuando por sus riñas fue desterrado allí por un año. Una poesía suya, "Otras suyas estando triste porque yua a vna aldea", a menudo se cita como prueba de su desdén y su irritabilidad:

I Nunca medreys vos aldea $y$ tambien quien os fundo porque tengo de estar yo donde nadie estar dessea Que qualquiera que me vea dira estoy mas retraydo que ninguno nunca a sido en mi linaje de Vrrea $[\ldots]$ If Pues andar siempre en la huerta tras zorzales con el arco bien veys que tan poco abarco ques cosa poco despierta Pues tal vida desconcierta el deleyte mas altiuo

${ }^{5}$ BOASE corrige la fecha comúnmente divulgada, 1508, y explica el error ("Inquiry", p. 37, n. 2). 


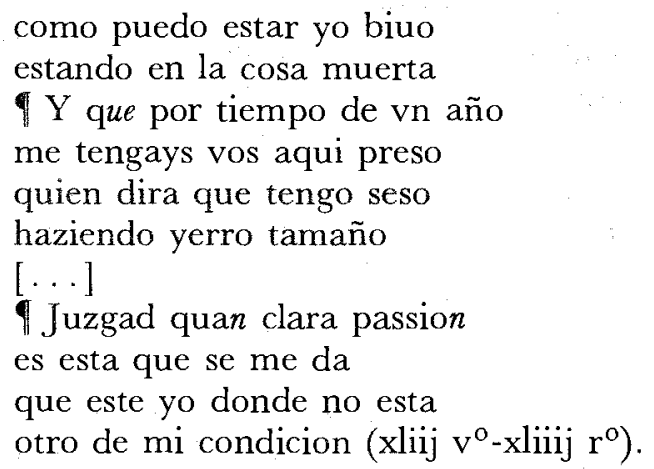

¡Cazar zorzales con arco y no jabalíes con venablo!: debe haberle atormentado verse caído en tal degradación.

Su deseo de aumentar su herencia fue abogado por su madre, doña Catalina de Híjar, quien inició un pleito contra el primogénito para mejorar la situación económica del segundón. Es este pleito el que sirve de foco de varias menciones que se encuentran en el Cancionero de todas las obras, algunas rencorosas, otras expresadas en términos que, por respetuosas que suenen, nos dan a entender su desafección, o sea aquella amargura de la cual habló Asensio. Nuestro autor le dedicó el nombrado cancionero de 1516 a su madre; en la carta que encabeza la colección hace hincapié en "las espessas fatigas y no pequeños trabajos que vuestra señoría ha tenido por crescer la pequeña parte que de mi padre me cupo"' (j r ${ }^{\circ}$ ). El que estuviera admirado de la empresa de su madre es patente: "en las cosas que vuestra señoria a hecho a mostrado mas varoniles fuerças que animo mujeril" ' $\left(\mathrm{j} \mathrm{v}{ }^{\circ}\right)$. Crea una sospecha sobre los motivos del hermano mayor - "los interesses ciegan la razon y hazen mas pobre el animo que rica la hazienda dexando por lo poco lo mucho" ( $\mathrm{j} \mathrm{r}^{\circ}$ ) - pero luego se retira de tal actitud, echándoles la culpa a los abogados:

Estos enojosos negocios de vuestra señoria por auer sido por pleyto se conosce claramente ser mas procurados por puntos de letratados [sic] que por voluntades delas partes porque ellos no pueden perder y oluidan la ganancia delos otros. Sobre lo qual dize muy bien Agustino que son como langosta que mordiendo daña y dañando destruye. Dize el poeta Eneas siluio. Los pleyteantes [sic] son las aues / el auditorio la era / el juez la red / los abogados los caçadores / y assi viendo vuestra señoria que el mayor huego desta vida es los pleytos deue dar gracias a dios que a salido. 
dellos conla concordia que entre tales personas y tal deudo sesperaua y tardaua $\left(j v^{\circ}\right)$.

El período de litigio debe haber coincidido en parte con el destierro a Trasmoz, o aquel lugar llegó a ser su domicilio acostumbrado por razón de penuria, pero por medio de su devoción a la poesía buscó un desahogo afectivo, como lo explica en una carta "Al muy illustre y magnifico señor don Luys de Yxar Conde de Belchite", su tío: "con la dulce poesia aliuio los amargos pensamientos que en mi moran causados por el triste pleyto que entre mi señora y el señor conde esta en lo qual nadie deue hablar. Pues el mal hablar daña: y el bueno no aprouecha" ( $x l r^{\circ}$ ).

Una larga cita más ofrecerá un ejemplo eficaz de cómo una frase florida puede conllevar un filo cortante:

mirando que aquello que errare [yo] vuestra señoria enmendara consiento algunas vezes poner por obra mi sobrada afficion compusiendo cosas que las hago no tanto con voluntad de presuncion como con desseo de seruir a mi señora que muestra holgar con esto y porque aora en esta sazon plugo a nuestro señor quitar cosa que tan mal parescia y poco montaua de los pleytos: vuestra señoria como siempre a tenido saber y discricion [sic] y conciencia a reperado [sic] el defecto de los letrados que ellos como todos los otros artistas buscan sus ganancias haziendo vna cosa tan fuerte y $\tan$ contraria que con vna misma ley conseja $n$ vna cosa a vno y otra a otro [...] alabado sea dios que en todo esto auemos puesto apartamento

Agora hallando me enesta aldea adonde faltan los passatiempos y sobran los enojos de ser la tierra fragosa mi vohuntad que me mouia y la tierra que me forçaua vue de yr cresciendo mi cancionero $\left(\mathrm{lv} \mathrm{v}^{0}\right)^{6}$.

Consciente del todo de ser miembro de una de las más notables familias de Aragón, sus apuros económicos le negaron acceso al mimado estilo de vida que claramente creía era suyo de derecho. Trasmoz, en su pobreza e ignorancia, puso en ridículo sus

${ }^{6}$ Hacia el fin de esta carta se encuentra un error tipográfico que dudo le hubiera gustado al conde: "Uuestra señora [sic] este mi trabajo resciba" (lvj $\mathrm{r}^{\circ}$ ). La referencia a presunción puede ser importante; en la Rueda de peregrinación la critica fuertemente: "assi como en los negocios desta vida la presuncion y yra quitan el conoscimiento y aquella passion no dexa ver lo justo assi en lo de dios la soberbia aparta la razon y la verdad"' (lxij $\mathrm{r}^{\circ}$ ). 
aspiraciones a una vida cortesana y siempre le acordó de lo que no poseía. Buscó escaparse en sus creaciones literarias, como lo explicó al conde de Belchite. No es que fuese consolado por completo por esto, porque también era consciente de que el "oficio" de bellas letras apenas compaginó con ser gentilhombre; en las dedicatorias en el Cancionero pide perdón de haberse rebajado a la creación artística y ruega que sus obras no lleguen al público para no convertirse en blanco de las críticas de aquéllos no capaces de apreciarlas. Como lo expresa en el prólogo a Penitencia de amor, "ay muchos que avn que no sepan ordenar saben sentir y por esto no deuria hombre escreuir nada: ni procurar trabajosa vana gloria dela pluma: pues ay otras cosas en que mas cauallerosamente se puede exercitar el entendimiento con otros passatiempos seguros de reprensiones"' (jx $\left.\mathrm{r}^{\circ}\right)^{7}$. Ironía o falsa modestia, nunca sabremos cuál, pero los deseos de doña Catalina, su madre, a quien dirigió estas palabras, al parecer prevalecieron, pues los frutos de su ocio impuesto fueron publicados.

Su producción literaria mantuvo los eslabones familiares, y no sólo por cartas y prólogos; Boase declara que sus villancicos "were undoubtedly sung to his own musical accompaniment" ("Poetic Theory", p. 101) $)^{8}$ y Asensio cree que sus églogas, "las primicias teatrales de Aragón"' (p. xi), fueron compuestas para representarse ante la familia: "[q]uizá en el palacio de Épila, residencia de su hermano el mayorazgo, subieron al tablado por vez primera los pastores del Moncayo, que - milagros de la tradición literaria- hablaban una lengua villanesca, más o menos sayaguesa"' (p. xii).

${ }^{7}$ AsEnsio comenta sobre la compenetración de persona y poesía: "Sus confidencias fluyen con la llaneza y abandono propios de una gran señor, para quien el arte es sólo un juego apasionante. Ha nacido poeta y se resigna [sic] ... Es una afición que no casa bien con su condición de ricohombre, ni cor las tradiciones aristocráticas de su familia. Quiere ser caballero, no juglar, n. literato" (p. xxv; la palabra ricohombre, aunque correcta en el sentido socia o jerárquico, es — ¿inconscientemente? - irónica en el económico). En unc carta dedicatoria que precede a sus villancicos y está dirigida a doña Beatría de Urrea, Condesa de Fuentes, Urrea habla de la cuestión del decoro: "nc dexo de embiar esto a vuestra merce por mucha pena que me da el ver se cuen. ta por especie de locura el trobar quando en mucha largura se estiende. $\mathrm{Y}$ ass es razon de entender hombre en otro. Porque el pensamiento deue estar lc mas del tiempo enlas cosas que aprouechan" (lxij $\left.\mathrm{v}^{\circ}\right)$.

8 "Poetic Theory in the Dedicatory Epistles of Pedro Manuel Ximéne: de Urrea (1486-c. 1530)", BHS, 57 (1980), p. 101; el adverbio "undoubtedly' - "sin duda" - puede que sea un poco sospechoso si uno acepta literalment 
Y no es sólo la primera égloga, la Naue, la que exhibe la misantropía del segundón ${ }^{9}$, pues en la segunda hay una clarísima instancia de la envidia de bienes; no podemos saber si ocurre también al principio de la pieza por igual razón de querer desahogarse personalmente - como las quejas de Mingo en Naue- ni si de propósito nombra al pastor Pedro, pero será imposible ignorar el vínculo sentimental entre dramaturgo y personaje:

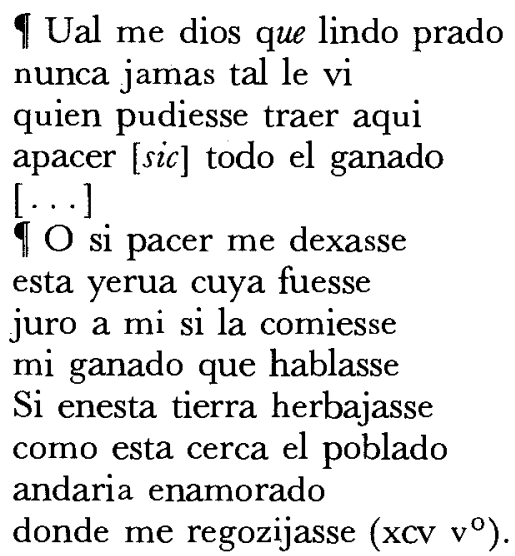

Las octavas que siguen ponen énfasis en la abundancia de la verdura, en la frescura del campo, y el pastor le dice a Pascual, saludándole, que "aqui se encierra / todo plazer y holgura" $\left(x c v j \mathrm{r}^{\circ}\right)$; los entrelazados sentimientos de envidia y carencia son tan fuertes en boca de Pedro que deben referirse a la propia estrechez del otro Pedro. Y si acabase de llegar al palacio desde aquel lugar de Trasmoz para presentar la égloga, si desempeñase el papel de Pedro él mismo, la referencia, en vez de ser semitransparente, la entendería todo el mundo sin dificultad alguna.

y no como modestia la declaración siguiente en la misma carta citada en la nota 7: "Porque en que se cantan paresce que lieuan consigo [los villancicos] mas plazer y bullicio que ninguna de las otras obras delo que yo siempre mas me [sic] contentado por lo poco que dela musica se" (lxij $\mathrm{v}^{\circ}$ ).

${ }^{9}$ En la introducción a mi edición crítica (University of Exeter, Exeter, 1990 [Exeter Hispanic Texts, 49]) del princeps de Penitencia de amor (Burgos, Fadrique, alemán de Basilea, 1514), sostengo que la misoginia predomina en esta derivación de Celestina; Urrea la desarrolla para que termine en la violación de Finoya por Darino, y el siguiente encarcelamiento de por vida para los dos. Esta variación de la misantropía no se aplica a las églogas, sin embargo, ni a la gran mayoría de sus poesías, algunas de las cuales defienden firmemente a las mujeres como sería de esperar en un género que sigue de cerca el tema del amor cortés. 
En la cuarta égloga dos pastores, un rufián y la pastora Pavina, se reúnen para un juego de maravillas cuyo propósito es un "mero pretexto para reflexiones sobre el desorden del mundo y la igualdad de los hombres ante los cuidados y la muerte"' (Asensio, p. xxxix), es decir, para ventilar los mismos sentimientos que en Naue. Empieza de esta manera:

$$
\begin{array}{ll}
\text { Solino. } & \text { Dadle comença primero } \\
\text { pues que el juego señalays } \\
\text { que assi como vos digays } \\
\text { dira todo compañero } \\
\text { Rufian. Yo marauillarme quiero } \\
\text { delo que fortuna siente } \\
\text { como por toda la gente } \\
\text { repartio mal el dinero }\left(\text { ciij } \mathrm{r}^{\circ}\right. \text { ). }
\end{array}
$$

Otra vez las octavas iniciales se compaginan mal con las dificultades amorosas de Solino, rechazado por su adorada Pavina ("Nunca me dexa dormir / tanto la quiero querer"' [cij vo]).

Presentar dos temas distintos en una de estas tempranas églogas no es insólito, como ya queda probado $^{10}$, de hecho, el emplear una pieza para expresar una queja personal tiene un claro antecedente en la petición de Juan del Encina buscando mayor reconocimiento de los Alba. La primera égloga de Urrea se destaca en virtud de los dos tonos distintamente opuestos, como ya hemos visto; también extraña encontrar, como en la cuarta égloga, un torrente de predicaciones sobre la moralidad dentro de conversaciones sayaguesas, en especial en una atmósfera lúdica; parece que en este caso la frase clave, "maravillarme quiero", fuc una tentación que Urrea no pudo rehusar.

Asensio ha notado (p. xxx) que el sentimiento de desengañc es más prevaleciente en las últimas creaciones de Urrea, y quc su obra en prosa Rueda de peregrinación ciertamente confirma la: convicciones religiosas del autor y un presentimiento (¿o deseo?' de algún castigo apocalíptico para la sociedad de su época, algc al estilo de la intervención divina pronosticada por el criado $\mathrm{Re}$ nedo en Penitencia de amor: "ya las cosas de virtud no pareçen; cor Dios subieron al cielo. Todos somos ya tan malos que ya es li fin del mundo, ya es nasçido el Antechristo. Todos somos tan per

${ }^{10}$ En mi estudio Love in the Early Spanish Theatre, Playor, Madrid, 1975 véanse esp. las pp. 86-87. 
uersos que Dios de muy enojado echará huego del çielo y acabará esta flaca vmanidad" (p. 29). Pero la misantropía es más o menos una constante en las obras de Urrea, y un impulso que también le lleva a la misoginia, como tan claramente demuestra Penitencia. Muy posible es que la religión le haya hecho centrar su visión moralizante en los pecados y ruindades contemporáneos; no por nada supone Boase que Pedro Manuel se hizo religioso en su madurez ("Inquiry", p. 45), pero el lector se confronta tantas veces con referencias a sus propias circunstancias personales - económicas y emocionales - que no puede dejar de ignorar un sabor de marginado en sus obras.

Si Mingo declara "querria yo andar do no me perdiesse" (xciij $\mathrm{v}^{\mathrm{o}}$ ), nuestro autor en su Batalla de amores mantiene que la búsqueda de soledad es el principio de la salvación: "Que la soledad avn que trae pensamientos que alos tristes quando estan solos haze desesperar / la compañia haze y causa mayores yerros porque estando solo tiene hombre su sola condicion / y acompañado a de seguir las agenas" (xxiiij vo ${ }^{\circ}$. Y aquí nos tropezamos con más de las ironías del hombre que fue Pedro Manuel Ximénez de Urrea Fernández de Híjar: por un lado la aridez de su domicilio en Trasmoz le repugna, por el otro estima mejor vivir aparte que ser contaminado por la maldad desenfrenada del mundo. Manda a Mingo a la extremadamente dudosa seguridad de la vida en la mar, pero a la vez de buena gana se haría miembro de una corte lujosa y animada, aun cuando censure la vanidad de los bienes materiales: "esta obra se llama rueda de peregrinacion porque to $=$ dos [sic] andamos peregrinando: y en rueda donde vemos los virtuosos por el suelo. Y los viciosos enla cumbre: pero al fin todos caemos: y donde despues nos hallamos vemos que los plazeres desta vida son pesares dela otra como la sagrada escriptura lo dize: que se enoja nuestra alma de nuestra vida" (lxj $\mathrm{r}^{\circ}$ ).

Hace más de un siglo Villar resumió el problema: "En verdad que el ingenio de Urrea merecía brillar en la corte más que estar encerrado entre los riscosos valles de Trasmoz o los solitarios campos de Illueca"' (p. xxiv) ${ }^{11}$. Sin embargo, si hubiera vivido con el lujo que abiertamente apetecía, por ejemplo allá en el palacio de Épila, es enteramente posible que no hubiese sentido la necesidad de escribir para aliviar los dolores ocasionados por la ley de la primogenitura, y así fácilmente habríamos perdido de

${ }^{11}$ Illueca habría sido otra herencia, pero Villar no aclara la referencia, no hay mención del lugar en el Cancionero de 1516. 
vista a uno de los más interesantes y enigmáticos hombres de las letras ibéricas del siglo XVI y no tendríamos todas esas obras tan curiosas, algunas de las cuales se han asomado en estas hojas. Al fin y al cabo, manda la fortuna y no la desvía el hombre: "veo que no se deue ni puede dar la culpa sino a la sola fortuna que por todos los estados de contino sin cansar va causando cosas que su nascimiento no esta fundado sobre razon y assi yo no quiero quexarme ni entristescerme si en esto a la fortuna por aduersaria he tenido pues que a nadie a dado saluo conduto" ( $\mathrm{xl} \mathrm{r}^{\circ}$ ). Pero sí se quejaba, se entristecía, y el Cancionero de todas las obras es el fruto agridulce que nos legó.

Robert L. Hathaway Colgate University 